\title{
AMOR (IN)CONDICIONAL: NOTAS SOBRE O COMING OUT DENTRO DE FAMÍLIAS EVANGÉLICAS
}

\author{
Karine Gouvêa Pessôa*
}

\begin{abstract}
RESUMO
Este artigo tem como objetivo apresentar algumas considerações acerca do relacionamento entre mães e pais e seus filhos e filhas tensionado pela descoberta da homossexualidade. Este texto fundamenta-se em entrevistas ${ }^{1}$ realizadas com gays e lésbicas, filhos e filhas de pessoas evangélicas. Considerando as representações correntes no meio evangélico sobre a homossexualidade e o sujeito homossexual, pretendemos apresentar o nexo entre essas representações e o comportamento performado pelas famílias dos entrevistados, e ao mesmo tempo enfatizar a presença de uma expectativa afetiva direcionada à família.
\end{abstract}

Palavras-chave: Religião. Família. Homossexualidade.

\section{(UN)CONDITIONAL LOVE: NOTES ABOUT THE COMING OUT INSIDE EVANGELICAL FAMILIES}

\begin{abstract}
The present article intent to present a few considerations about the relationship between mothers and fathers and their sons and daughters related to the discovery of the homosexuality. This text is based on interviews with gays and lesbians sons and daughters raised by evangelic families. Considering the general representations in the evangelical everyday life speech about homosexuality and the homosexual individual, we intend to demonstrate the link between these representations and the behavior performed by the families
\end{abstract}

* Mestra em Sociologia Política pelo Programa de Pós-Graduação em Sociologia Política da Universidade Estadual do Norte Fluminense (PPGSP/UENF) e bacharela em Ciências Sociais pela Universidade Federal Fluminense (UFF/2014). Atualmente estuda família, religião e homossexualidade. A pesquisa da qual derivou o artigo iniciou-se em janeiro de 2016, sendo autorizada pelo Programa de Pós-Graduação em Sociologia Política da UENF, uma vez que a universidade não dispõe de um comitê de ética em pesquisa com seres humanos. 
of the interviewers, and at the same time emphasize the presence of an affective expectation towards to the family.

Key-words: Religion. Family. Homosexuality.

\title{
AMOR (IN)CONDICIONAL: NOTAS SOBRE EL COMING OUT DENTRO DE FAMILIAS EVANGÉLICAS
}

\begin{abstract}
RESUMÉN
El presente artículo tiene como objetivo representar algunas consideraciones sobre la relación de madres y padres con sus hijos e hijas acerca del descubrimiento de la homosexualidad. Este texto se fundamenta en entrevistas realizadas con gays y lesbianas hijos e hijas de personas evangélicas. Considerando las representaciones corrientes en el medio evangélico sobre la homosexualidad y el sujeto homosexual, pretendemos presentar el enlace entre esas representaciones y el comportamiento realizado por las familias de los entrevistados, y al mismo tiempo enfatizar la presencia de una expectativa afectiva que se dirige a la familia.
\end{abstract}

Palabras-clave: Religión. Familia. Homosexualidad.

\section{INTRODUÇÃO}

Os debates suscitados nos últimos anos, decorrentes de pautas progressistas direcionadas à população LGBT, aqueceram os conflitos na política nacional. A contraposição levada a cabo por grupos religiosos que se opuseram a proposições como a união estável de casais do mesmo sexo, ao kit anti-homofobia, à PLC 122/06 que criminaliza a homofobia e são favoráveis à aprovação do Decreto Legislativo 234/11, que versa sobre a Terapia de reorientação sexual, popularmente conhecida como cura gay, revelou muitas das representações correntes no meio evangélico acerca da homossexualidade.

Essas disputas travadas dentro do sistema político, longe de permanecerem ali insuladas, espalham-se por todo o tecido social. Os debates que são travados nos espaços de disputa política disseminam-se pela sociedade. Esses debates extrapolam os limites da laicidade, uma vez que estão atravessados por argumentos religiosos que, contudo, são reproduzidos tanto por religiosos quanto por conservadores não religiosos. 
Neste trabalho, pretendemos apresentar as representações acerca da homossexualidade e do indivíduo homossexual que têm sido veiculadas por setores religiosos e seus possíveis impactos na esfera familiar, tendo como lócus da observação famílias evangélicas com filhos gays e filhas lésbicas. Apresentaremos algumas notas acerca do relacionamento familiar de indivíduos inseridos em dinâmicas de conflito dentro de suas famílias. As situações aqui colocadas derivam-se da tensão gerada no núcleo familiar devido à descoberta da homossexualidade. Os entrevistados são gays e lésbicas filhos e filhas de pessoas evangélicas. Por intermédio da análise dos eventos vividos pelos entrevistados, bem como, do estudo acerca das representações correntes no meio evangélico a respeito da homossexualidade e sobre o sujeito homossexual, estabelecemos aqui nexo entre elas.

\section{OS EVANGÉLICOS NA POLÍTICA}

A entrada expressiva dos evangélicos na política brasileira tem início na ocasião da Constituinte. As lideranças pentecostais buscavam, por meio dela, "fazer valer a sua voz, até então restrita aos templos privados, ampliando assim seus valores para uma maior parte da população brasileira" (Janine TREVISAN, 2013, p. 3). Ao mesmo tempo em que alegavam temer que a nova Constituição colocasse em risco a liberdade religiosa alcançada em 1890, estavam receosos com a possibilidade de que grupos LGBT conseguissem regulamentar na nova constituição alguns direitos, como o casamento homoafetivo. Essa preocupação advinha de um intenso trabalho de convencimento, onde, segundo seus porta-vozes, as igrejas evangélicas estariam na iminência da ameaça à liberdade religiosa e à família. ${ }^{2}$ Sendo assim, desde o início de sua participação na política, o posicionamento dos evangélicos é marcado pela oposição a propostas que divergiam de seus princípios religiosos.

Alguns eventos marcam o início do recrudescimento das ações de grupos religiosos contra a ampliação de direitos a pessoas LGBT. Para

A exemplo disso, Paul Freston evidencia que líderes da Assembleia de Deus, em 1986, trabalhavam com a ameaça à liberdade religiosa (por ameaça direta da Igreja Católica) e à família (pela legalização do aborto, drogas, casamento homossexual, festivais de rock) a fim de convocar os fiéis a votarem em outros "irmãos" (1993, p. 216). 
Ramos (2014), o reconhecimento pelo STF da união estável de casais homossexuais em maio de 2011, é o evento que marca o principal confronto entre grupos religiosos e movimentos feministas e LGBT.

Ainda em maio desse mesmo ano, a presidenta Dilma optou por vetar um programa do Ministério da Educação destinado ao combate da homofobia nas escolas. O kit anti-homofobia (batizado pelos opositores de "Kit-gay"), compreendia vídeos e textos direcionados a professores com adolescentes em situações relacionadas à homossexualidade e discriminação contra homossexuais. O material enfrentou grandes críticas de jornais e foi combatido por deputados federais evangélicos e conservadores.

Ramos (2014) evidencia que nas eleições municipais de São Paulo, em 2012, o pastor Silas Malafaia faz a tentativa de inserir um viés religioso na eleição trazendo à baila novamente as críticas acerca do pejorativamente apelidado kit-gay. ${ }^{3} \mathrm{O}$ pastor declarou apoio ao candidato José Serra, ao mesmo tempo em que convocava os evangélicos "a atacarem Haddad por ter sido sob sua direção no Ministério da Educação que foi desenvolvido o kit anti-homofobia" (Jair RAMOS, 2014, p. 4).

Em dezembro de 2011, a PLC 122/06, que criminalizaria a homofobia foi retirada, encerrando a tentativa de quase uma década de aprovar uma lei que reconhecesse a homofobia como crime de ódio.

A eleição para a presidência da comissão de Direitos Humanos e Minorias da Câmara Federal, em fevereiro de 2013, reacendeu os conflitos. Ramos (2014) explica que:

Ao final de fevereiro, no início da nova legislatura, os partidos políticos com representação na Câmara se articularam para dividirem os cargos nas comissões parlamentares e fecharam um acordo em que o PT abriu mão da Comissão de Direitos Humanos e Minorias, para priorizar outras comissões, deste modo, o PSC ficou com o direito de indicar o presidente. A escolha do PSC recaiu sobre o Pastor Marco Feliciano, um dos deputados mais radicais do ideário religioso-conservador no congresso. Sua escolha representou uma ruptura histórica na comissão de direitos humanos quem desde a sua criação, havia

O candidato à Prefeitura de São Paulo pelo Partido dos Trabalhadores foi Fernando Haddad, que na ocasião do debate acerca do kit anti-homofobia era Ministro da Educação. 
sido dirigida por deputados identificados com o campo da luta dos direitos humanos e das minorias, especialmente sensíveis às demandas dos movimentos feministas e LGBT (Jair RAMOS, 2014, p. 4-5).

Segundo Ramos, "em torno dos eventos acima, se estruturam embates políticos e simbólicos que são produto e produzem os grupos que se enfrentam em torno do reconhecimento estatal de direitos sexuais" (Jair RAMOS, 2014, p. 5). Para o autor:

...a defesa da família e o controle sobre a sexualidade vão se tornar progressivamente temas políticos. Nesse sentido, a política brasileira nesse início do século XXI vai testemunhar o confronto entre pautas e agentes políticos que se organizam de fora do estado e tomam a sexualidade como um objeto de intervenção estatal (Jair RAMOS, 2014, p. 6-7).

A fim de identificar a origem dos discursos utilizados na oposição e a ampliação de direitos para a população LGBT, Trevisan (2015) identifica algumas similaridades entre o que ela chama de núcleo duro da Frente Parlamentar Evangélica com a Direita Cristã estadunidense. A primeira delas está relacionada à entrada dos pentecostais na política nacional, que fora "despertada pelo medo, pela incerteza política e pela sua certeza moral íntima” (Ariel FINGUERUT, 1999 apud Janine TREVISAN 2015, p. 65). A segunda similaridade é a utilização de uma retórica em torno de uma suposta "estratégia gay", que planeja transformar a sociedade, pondo em risco os valores morais cristãos.

Freston (1993, p. 216) evidencia a presença de um argumento acerca da iminência dos mais variados riscos. Sendo os principais o risco à liberdade religiosa e à ameaça à família. Era nessas ameaças que estavam fundadas as candidaturas de evangélicos, bem como, a obrigação moral em votar nos "irmãos". Dessa forma, seu engajamento justificava-se na defesa de seus valores. Drogas, aborto, imoralidade, casamento homossexual, festivais de rock entravam na lista de coisas a serem combatidas.

Trinta anos se passaram desde então, e a pauta continua muito semelhante, bem como, os argumentos. A suposta ameaça, sempre 
presente, em retirar sua liberdade religiosa ainda funciona com eficácia. ${ }^{4}$ Na ocasião da PLC 122/06, pejorativamente apelidada por seus opositores como a lei da "mordaça gay", estes argumentavam e disseminavam a ideia de que o projeto de lei pretendia realizar uma censura na Bíblia, de forma que com a criminalização da homofobia, acreditava-se que a lei seria usada também para prender os que pregavam contra a homossexualidade. Mesmo com a inclusão do artigo $3^{\circ}$., que afirmava que:

O disposto nesta Lei não se aplica à manifestação pacífica de pensamento decorrente da fé e da moral fundada na liberdade de consciência, de crença e de religião de que trata o inciso VI do art. $5^{\circ}$. da Constituição Federal.

A retórica da censura foi amplamente utilizada na mídia evangélica. Silas Malafaia, em seu programa de televisão, dedicou inúmeros programas para abordar a PLC 122, onde o argumento da liberdade religiosa foi utilizado. Segundo o pastor:

A PL 122 quer criminalizar os que são contra a prática homossexual (...) É a lei do privilégio (...) Quer atingir crença, quer atingir direito de expressão. Querem criminalizar opinião. ${ }^{5}$

De maneira semelhante à oposição proativa norte-americana, que no início da década de 1990 deu início a uma campanha "no special rights", os oposicionistas da PL 122 utilizaram a argumentação da inconstitucionalidade, uma vez que por meio da PL se criariam privilégios para os homossexuais, "em detrimento dos religiosos que teriam sua opinião silenciada" (Janine TREVISAN, 2015, p. 166). "Gays não querem direitos, mas privilégios". Esse célebre argumento já foi professado por figuras públicas como Silas Malafaia ${ }^{6}$ e parlamentares, entre eles Jair

Trevisan (2015) em sua tese de doutorado analisa o "jogo de estratégias" desempenhado entre evangélicos e seus opositores nos espaços políticos a fim de aprovarem suas proposições. Aqui estamos mais preocupados com os argumentos utilizados pelos evangélicos para informar a sociedade civil.

5 Disponível em: <https://www.youtube.com/watch?v=jA54CXmEBys >. Acesso em: 27 fev. 2017.

6 Disponível em: <https://twitter.com/pastormalafaia/status/319282943463923713>. Acesso em 25 fev. 2017. 
Bolsonaro7 e Magno Malta ${ }^{8}$ na ocasião dos debates acerca da PLC 122. Segundo Trevisan, "embora o argumento central contra as iniciativas do governo tenha seu fundo de moralidade cristã, a Frente Parlamentar Evangélica utiliza outros recursos discursivos, no sentido de distanciar-se das acusações de que seria apenas um grupo de pressão religiosa" (Janine TREVISAN, 2015, p. 182). Essa estratégia lhes permite alcançar também conservadores não religiosos.

Além do trabalho realizado no Congresso Nacional, a Frente Parlamentar Evangélica passou a organizar encontros, tendo como objetivo aproximar a população das pautas debatidas na Câmara. As Jornadas Nacionais em defesa da Vida e da Família organizadas desde 2007 abordavam temas como:

...liberdade religiosa, ameaçada pela "ditadura gay" que o PLC 122/2006 tentava implementar no Brasil, a desconstrução da heteronormatividade e a consequente destruição da família brasileira, imposta pelo PNDH III e pelo Ministério da Educação que, através dos livros didáticos que apresentam diferentes modelos de família, na visão dos evangélicos, busca impor a homossexualidade para as crianças. Além disso, também se discutiu sobre o "infanticídio indígena", com a presença de pastoras indígenas, os programas de redução de danos do Ministério da Saúde que visam, através das suas cartilhas ensinar/estimular as crianças a usarem drogas e praticarem relações promíscuas, etc. (Janine TREVISAN, 2015, p. 188, nota de rodapé).

Segundo Trevisan, os eventos se davam fora do Congresso e se articulavam com lideranças religiosas, para estas, "repassarem suas informações e argumentos aos seus fiéis os quais, por sua vez, acabam investindo seus votos em parlamentares ligados às igrejas evangélicas" (Janine TREVISAN, 2015, p. 189). O papel de politização das igrejas fica evidente aqui, uma vez que as discussões apresentadas aos fiéis refletem as perspectivas da Frente Parlamentar Evangélica.

7 Disponível em: <https://noticias.terra.com.br/brasil/politica/bolsonaro-sobre-casamento-gay-nao-querem-igualdade-e-sim-privilegios, $99 \mathrm{ff} 52 \mathrm{~d} 635$ aae310VgnVCM400000 9 bcceboaRCRD. html>. Acesso em 25 fev. 2017.

8 Disponível em: <http://blogs.odiario.com/inforgospel/2013/11/26/magno-malta-pastorsenador-discursa-pl122-chama-atencao-evangelicos-assista/>. Acesso em 25 fev. 2017. 
Considerando os apontamentos realizados por Trevisan (2015) acerca das Jornadas Nacionais em defesa da Vida e da Família promovidas pela Frente Parlamentar Evangélica, a distância entre estes e igreja é diminuída, de forma que passam a compartilhar os objetivos de propagar suas crenças e ideias a respeito da diversidade sexual, estabelecendo uma relação de interdependência. Uma vez que a necessidade de votar em indivíduos que professam a mesma fé reside na necessidade de defesa de instituições que segundo os que disseminam esses discursos estariam em risco, garante-se a permanência dos que disseminam e utilizam tais argumentos. Sem o risco à família e à liberdade de expressão, talvez a necessidade em eleger candidatos cristãos não existiria. Daí a necessidade em disseminar certo terrorismo ${ }^{9}$ circundante à ampliação de direitos a pessoas LGBT.

Apesar do panorama apresentado de tensões entre líderes evangélicos e movimentos LGBT, ele não é suficiente para compreender a influência dessas articulações nas esferas privadas, uma vez que esta goza de certa autonomia. Entretanto, tampouco podemos afirmar que o trabalho levado a cabo por setores evangélicos, na disseminação de um imaginário bem pontual a respeito da homossexualidade e dos indivíduos homossexuais, não exerça qualquer influência na vida familiar dos que em alguma medida enxergam em bispos e pastores representantes de Deus na Terra.

As representações da homossexualidade e do sujeito homossexual veiculadas dentro das igrejas evangélicas são das mais variadas. Entretanto, aqui nos propomos a apresentar as representações predominantes no meio evangélico.

\section{A HOMOSSEXUALIDADE SOB PERSPECTIVAS EVANGÉLICAS}

A gênese da compreensão sobre o pecado concernente à homossexualidade é atribuída pelos líderes religiosos à Bíblia. Passagens bíblicas são evocadas a todo momento a fim de justificar a condenação

Natividade e Oliveira (2013) revelam que uma retórica construída em torno da ideia da destruição de Sodoma era utilizada na ocasião dos debates sobre a PLC 122, de forma que o mesmo castigo poderia sobrevir ao Brasil caso os cristãos não se mobilizassem para conter a ampliação de direitos à população LGBT. 
imputada às práticas homossexuais. Os protagonistas dessa propagação vão desde líderes religiosos a fiéis.

Muito embora o catolicismo, o mormonismo e outras religiões também utilizem a Bíblia, o tema homossexualidade se revela um fenômeno no meio evangélico. Livros, CD's, DVD's de pregação, palestras e workshops são dedicados inteiramente a dissertar sobre essa questão, ${ }^{10}$ abordando desde a origem da homossexualidade ao indivíduo homossexual. A homossexualidade é condenada pelo cristianismo desde sua invenção, ${ }^{11}$ e apesar de existirem ministérios com visões diferenciadas, podemos considerar que, quando o assunto é homossexualidade, existe considerável uniformidade discursiva entre distintas denominações evangélicas.

Setores evangélicos têm se mobilizado a fim de criar entidades com a função de promover seus interesses. A exemplo disso grupos como o Corpo de Psicólogos e Psiquiatras Cristãos (CPPC) e a Associação Brasileira de Apoio a Pessoas que Voluntariamente Desejam Deixar a Homossexualidade (ABRACEH), funcionam como aconselhadores, bem como, formadores de líderes para lidar com questões referentes à homossexualidade no meio evangélico, produzindo livros e artigos com esse objetivo. Estes compartilham de um discurso comum acerca da homossexualidade permeado pela ideia de cura. Muito embora saibamos que o discurso hegemônico não corresponde à totalidade entre os líderes evangélicos, este se constitui como discurso predominante.

10 Como A estratégia: o plano dos homossexuais para transformar a sociedade, do Rev. Louis P. Sheldon (2012), As ilusões do movimento gay e O movimento homossexual, ambos de Julio Severo (2003; 1998).

11 Vale ressaltar que o Antigo Testamento só faz referência à sodomia como prática condenável. As práticas sexuais lésbicas não são mencionadas. Sobre isso Endsjø (2014) afirma que, como em outras religiões, como judaísmo, islã, hinduísmo e budismo, a sexualidade feminina só pode ser definida à medida que se relaciona com um homem (devido à necessidade de existir penetração para ser considerado sexo), e é pelo fato do lesbianismo não envolver homens que ele acaba por ser ignorado ou mesmo considerado irrelevante. Já no Novo Testamento, Paulo insere a prática sexual entre mulheres no mesmo patamar da prática sexual entre homens (Romanos 1:26). Entretanto, a ênfase dada sobre a homossexualidade masculina ainda é prevalecente na literatura evangélica acerca da homossexualidade (NATIVIDADE, 2006). 
Marcelo Natividade realizou uma análise das representações acerca da homossexualidade, ${ }^{12}$ tendo como objeto de investigação a produção literária evangélica acerca da homossexualidade, incluindo falas de líderes religiosos realizadas em cultos pentecostais e constatou a recorrência de algumas afirmações referentes a ela:

1) trata-se de um comportamento aprendido; 2) de um problema espiritual; 3) é uma antinatureza. Tais conceitos sustentam um posicionamento mais geral dos evangélicos de que o homossexualismo não representa um atributo "natural" do sujeito. Subjacente à concepção de que estas práticas podem ser abandonadas pela restauração e cura, há a ideia de uma natureza heterossexual (Marcelo NATIVIDADE, 2006, p. 118).

No material analisado por Natividade, é possível perceber a existência de um discurso hegemônico que é propagado dentro das igrejas, onde as três concepções a respeito das causas da homossexualidade coexistem permeadas pela possibilidade de reversão à forma considerada perfeita - a forma heterossexual.

A adoção de um posicionamento construtivista por parte dos evangélicos deixa margem à possibilidade de gerenciamento dos corpos na produção de uma sexualidade dentro dos limites determinados pela doutrina. Afirmar que o impulso homossexual tem origem em fatores ambientais ou espirituais é justamente o que permite o controle das condutas sexuais pela promessa de reversão da homossexualidade. A concepção evangélica, assim, conforma-se como um construtivismo moral, que em outro plano discursivo recorre a argumentos naturalistas em sua definição do gênero (Marcelo NATIVIDADE, 2006, p. 120).

Tais concepções corroboram ideias que habitam o imaginário coletivo, onde as sexualidades dissidentes da norma heterossexual estão localizadas junto às perversões sexuais. Natividade aponta que no material impresso analisado há inúmeras referências ao estilo de vida

12 Natividade (2006) ressalta que na maioria dos trabalhos, bem como, sermões, a homossexualidade masculina ocupa lugar de destaque, de forma que muitas vezes o lesbianismo sequer é mencionado. 
gay, em que o comportamento homossexual é "desordenado, imoral e que conduz ao sofrimento" (Marcelo NATIVIDADE, 2006, p. 118), além de serem dados às perversões sexuais e à promiscuidade. São inúmeras as falas que relacionam a homossexualidade à pedofilia. Alguns militantes associam o suposto aumento no número de homossexuais ao crescimento nas taxas de pedofilia, bem como, responsabilizam as pessoas homossexuais pela disseminação da Aids e outras DST (Marcelo NATIVIDADE; Leandro de OLIVEIRA, 2013, p. 91). A homossexualidade estaria relacionada a uma transfiguração maligna de gênero, uma vez que as narrativas apresentam a questão da inversão do gênero.

As abordagens acerca da origem da homossexualidade, em geral, rejeitam a ideia da existência de uma predisposição ou mesmo tendência inata à homossexualidade, de forma que afirmam "o primado das influências ambientais, sociais e psicológicas na conformação das identidades homossexuais" (Marcelo NATIVIDADE, 2006, p. 118). Entre as concepções mais singulares, uma compreende que fatores como o abuso sexual na infância, dificuldades de relacionamento com pai e mãe, e o que o autor chama de "relacionamento deficiente com o genitor do mesmo sexo" propiciariam sua eclosão. A heterossexualidade é compreendida como condição natural do sujeito, no entanto nessa perspectiva, os homossexuais a desafiam com suas práticas.

É importante enfatizar que não existe uma visão unívoca sobre as formas de lidar e compreender a homossexualidade no meio evangélico. Acerca de uma suposta uniformidade de pensamento entre os evangélicos, Machado e Piccollo (2010) mencionam o desenvolvimento de uma teologia queer por um grupo de teólogos luteranos, bem como, o surgimento das igrejas "inclusivas" no segmento histórico. Fica manifesto aqui que, apesar de se ouvir com mais clareza e frequência um discurso mais intransigente e fundamentalista sobre a homossexualidade, outras vozes têm despontado trazendo visões diferenciadas. Entretanto, é preciso evidenciar que estes ocupam espaço diminuto nesse universo.

O trabalho de mobilização de preconceitos promovido pelos setores mencionados apresenta impacto na opinião pública, sobretudo entre os evangélicos. Se na propaganda contra a homossexualidade e direitos dos homossexuais disseminado por meio de outdoors e em programas de 
TVs seculares é lançado mão na maior parte das vezes um discurso que argumenta sobre a limitação de direitos e corrupção moral da sociedade, o argumento utilizado entre seus pares se agudiza, chegando a versar sobre a destruição da humanidade provocado pelo comportamento homossexual. As consequências desses discursos na esfera privada notadamente desencadeiam conflitos dentro das famílias. A moralidade religiosa não opera em contexto desprovido de expectativas morais. Ela encontra um contexto de interações e vínculos estruturados também pela moralidade afetiva que é acionada como fonte de reconhecimento social na esfera das relações de intimidade (Axel HONNETH, 2003, p. 159). É sobre o encontro da moral religiosa e com essa moralidade das relações de intimidade que trataremos adiante.

\section{EXPECTATIVAS E FRUSTRAÇÕES ORIGINADAS PELO COMING OUT}

As entrevistas foram realizadas com pessoas entre 18 e 32 anos de idade que já realizaram o coming out ${ }^{13}$ para as suas famílias, verbal ou vivencialmente. Os entrevistados foram localizados por meio de posts em coletivos LGBT da cidade de Campos dos Goytacazes/RJ ${ }^{14}$ em rede social, onde a pesquisa foi apresentada, convidando gays e lésbicas filhos e filhas de pessoas evangélicas a participar das entrevistas. Utilizamos a técnica bola de neve para ampliar a possibilidade de acesso ao grupo pretendido. A análise das entrevistas feitas aponta para algumas questões que serão pontuadas adiante. A revelação de sua sexualidade tem se desdobrado na maioria dos casos na quebra de uma fantasia atribuída à família, mais especificamente à figura do pai e da mãe como portadores do amor incondicional. Nem todos os entrevistados realizaram o coming out voluntariamente. Entretanto, os que o fizeram, relataram contar com esse amor incondicional no momento da revelação de sua sexualidade. Mesmo sabedores de que seria um momento de conflito familiar, acreditavam que passariam por ele sem grandes danos. Contudo, entre os nove entrevistados, sete declararam não se sentir aceitos por seus pais e mães. Três deles foram agredidos

Por coming out nos referimos ao ato de revelar sua orientação sexual publicamente.

14 As entrevistas aconteceram entre janeiro de 2016 e março de 2017, tendo sido realizadas na cidade de Campos dos Goytacazes, no Estado do Rio de Janeiro. 
na ocasião da revelação da homossexualidade ou em momento posterior em virtude dela, e uma teve o auxílio financeiro retirado semanas após a revelação, após a recusa de se mudar para outro Estado com eles.

As leituras que filhos e filhas fazem do comportamento parental são das mais variadas. Enquanto alguns revelam grande sofrimento diante da relação ainda deteriorada com a família e creem que a religião apresenta papel fundamental na não aceitação, outros acreditam que a religião desempenha função tanto na não aceitação (relacionada às passagens bíblicas que condenam a homossexualidade), quanto na aceitação (por meio da ideia da incondicionalidade do amor de Cristo) e confiam que dentro de algum tempo um bom relacionamento será estabelecido. Entre os entrevistados que não se sentem aceitos por seus pais e mães, todos atribuem a não aceitação à questão religiosa, que acaba aparecendo nos discursos proferidos pelos pais e mães. Falas como "você vai pro inferno", "Deus abomina", "Deus pode curar" foram ouvidas relacionadas à homossexualidade, e acabam por embasar as percepções filiais.

As reações diante da descoberta da homossexualidade são variadas. Enquanto alguns pais e mães expressam com clareza seu desagrado, outros preferem ignorar a questão e não discuti-la passado o momento do coming out. $\mathrm{O}$ ato de ignorar, simular o desconhecimento da sexualidade de seus filhos (Didier ERIBON, 2008), aparentemente funciona como ferramenta para facilitar a convivência, contudo se alguns filhos interpretam a atitude como aceitação, pois segundo estes, se fosse um problema a mãe já o teria abordado, outros entendem que essa atitude só tem como objetivo evitar o conflito, dado que muitos ouvem críticas à homossexualidade endereçadas a outras pessoas, mas entendem essa atitude enquanto uma forma de deixá-los cientes de sua insatisfação, suas crenças e anseios.

Entre os nove entrevistados, sete relataram não ter abertura para conversar sobre sua vida amorosa com sua família. Aparentemente, um mecanismo desenvolvido para continuarem a conviver com seus filhos e filhas é a negação e/ou não tematização de sua sexualidade, como já colocado. Em geral, a família não faz mais perguntas sobre namorados ou namoradas desde que tomaram conhecimento de sua sexualidade. 
Somente dois entrevistados apresentaram um namorado às famílias muito embora alguns já os tenham apresentado enquanto amigos. Esse tipo de comportamento adicionado a um discurso que avilta a identidade homossexual, intimida alguns a não expressar mais abertamente sua vida afetivo-sexual, dado que muitos deles ainda são financeiramente dependentes de suas famílias e dizem se sentir pressionados a viver essa área de sua vida de maneira mais discreta, sob pena de não receber mais ajuda financeira.

$\mathrm{Na}$ atuação de algumas mães e pais, filhas e filhos percebem uma discrepância entre o que é esperado para o papel social destes enquanto pais e mães e o seu comportamento efetivo diante do coming out. O desempenho da maioria das famílias não reflete os valores e comportamentos sociais esperados do papel social de pai e mãe. Acerca desses, espera-se que eles expressem alguns valores comuns da sociedade atribuídos a este papel social, como cuidado, amor e compreensão, e não abandono, agressões e rejeição. Quando mães e pais performam ações que rejeitam características identitárias de seus filhos e filhas, enviam a mensagem de que aquela parcela específica da identidade não pode ser aceita por eles, e que, por isso, devem corrigi-las se desejam gozar de todos os benefícios (materiais e afetivos) que são concedidos aos que atendem às expectativas. No momento em que o pai e a mãe de uma entrevistada colocaram como condição, para ela receber auxílio financeiro, a submissão aos seus desejos, exigindo que ela se mudasse com eles para uma nova cidade, não o fizeram ancorados em uma expectativa moral de seu papel social de pai e mãe, mas usaram de coerção a fim de fazê-la obedecer. Ao mesmo tempo, quando os filhos se negam a obedecer e aceitar as condições impostas pela sua parentela, colocam à prova a incondicionalidade do amor materno/paterno, que com frequência tem resultado na ruptura da representação para este papel social.

Uma regularidade apresentada é a importância dos amigos, como grupo de apoio. A maioria dos entrevistados, diante do hiato familiar, busca por construir para si uma família, ainda que sem laços consanguíneos, baseada puramente em trocas afetivas, corroborando o ideal de relacionamento puro. Muitas das definições de família como "quem acolhe", "quem cuida", "pessoas com quem você mantém um laço de 
afeto forte", "união de pessoas que cuidam uma da outra", mostram que a via afetiva é privilegiada no momento da significação. Sobre isso Eribon identifica a "família de substituição": segundo ele, os gays são impelidos à "substituição dos laços 'naturais' e familiares por laços construídos e escolhidos" (Didier ERIBON, 2008, p. 51), não necessariamente por serem excluídos forçosamente do meio familiar, mas por vezes devido à dificuldade em manter com sua família uma convivência harmoniosa. De acordo com Eribon:

...o círculo de amigos está no centro das vidas gays, e o percurso psicológico (e, com frequência, geográfico) do homossexual marca uma evolução da solidão pra socialização em e pelos lugares de encontro (sejam os bares ou os parques). Assim, o modo de vida homossexual está fundado nos círculos concêntricos das amizades ou na tentativa de sempre recomeçada de criar tais redes e de estabelecer tais amizades (Didier ERIBON, 2008, p. 39).

O sentimento de desencaixe da família consanguínea promove a busca por novas formas de arranjos. Não necessariamente a pessoa romperá com a família e constituirá outra em novos moldes, mas quanto ao cumprimento da função de relacionamento afetivo descrita pelos próprios entrevistados ("onde você é acolhido", "onde você é compreendido"), essa busca será direcionada a esse grupo formado por amigos. As expectativas vinculadas ao ideal de relacionamento puro são deslocadas do grupo familiar consanguíneo para a "família de substituição", promovendo, desse modo, ao invés da negação, uma reafirmação transformadora da ideia normativa de amor incondicional. Portanto, nos momentos em que o indivíduo necessita desse apoio afetivo sua demanda será direcionada a esse segundo grupo.

O fundamental é ter alguém para desempenhar o papel antes circunscrito à família consanguínea. ${ }^{15}$ Quando os que se sentem desamparados pela família consanguínea conseguem, por meio de novos arranjos, receber a segurança que supostamente viria da consanguinidade, a compreensão é que se tem uma família novamente.

15 Vale dizer que uma das entrevistadas já teve que realizar esse processo anterior à revelação da homossexualidade, visto que fora adotada na adolescência. 
Um problema que perpassa essa questão é que, por vezes, os que desempenham essa função são namorados e namoradas, e dada a característica transitória dos relacionamentos, a cada término possivelmente inicia-se outra crise emocional. Uma das entrevistadas relatou que, após entrar em depressão, em virtude do rompimento com a família, onde a mãe ficou nove meses sem falar com ela, a namorada foi seu suporte, e para quem transferiu toda sua dependência emocional. Na ocasião do término do namoro, outra crise sucedeu. Segundo a entrevistada, ela se viu novamente sozinha.

É fundamental mencionarmos aqui a existência de duas famílias que acolheram seus filhos diante da revelação da homossexualidade. Inclusive, entre os entrevistados que declararam se sentir aceitos, nenhum deles ouviu em algum momento sugestão de cura ou mesmo críticas. Essas famílias encerram em si o ideal de relacionamento puro desenvolvido por Giddens, uma vez que seguiram com o relacionamento, esforçando-se por manter intacto o tratamento dado aos seus filhos, por mais que a homossexualidade não se constitua como elemento positivo para eles, em função de sua socialização com uma moral religiosa que quase sempre condena a homossexualidade. Segundo o autor, há uma nova gramática orientando as relações familiares pautada no ideal democrático. A partir daí o autor introduz o conceito de relacionamento puro, o qual define como "um relacionamento baseado na comunicação emocional, em que as recompensas derivadas de tal comunicação são a principal base para a continuação do relacionamento" (Anthony GIDDENS, 2007, p. 70). Sobre isso afirma que diferente dos tipos mais tradicionais de laços sociais, o relacionamento puro "depende de processos de confiança ativa - a abertura de si mesmo para o outro. Franqueza é a condição básica da intimidade. O relacionamento puro é implicitamente democrático" (Anthony GIDDENS, 2007, p. 70).

Em situações controversas desencadeadas pelo coming out de um filho gay ou filha lésbica em famílias com pai e/ou mãe evangélicos, o conflito entre a moral religiosa e a moralidade do relacionamento puro não possui desfecho necessário, embora se possa esperar a predominância de uma não aceitação estável da homossexualidade dos filhos e filhas. A força relativa de cada moralidade - a religiosa e a do relacio- 
namento puro - não está dada; ele se mostra e se constrói no processo conflituoso do coming out podendo a moralidade do relacionamento puro, muitas vezes se sobrepor ao que as religiões prescrevem sobre a homossexualidade.

\section{CONSIDERAÇÕES FINAIS}

A preocupação dos males oriundos da vivência num contexto social ameaçador à sua sexualidade é latente devido às suas consequências danosas à saúde mental e qualidade de vida de gays e lésbicas. Num contexto familiar imerso numa cosmologia religiosa como a evangélica, algumas barreiras por vezes parecem fortalecidas por essa cosmologia. No entanto, a religiosidade aparentemente não se impõe enquanto fator esmagador da reflexividade do indivíduo. Por meio das entrevistas, foi possível perceber reações das mais variadas diante da homossexualidade de um filho ou filha. Enquanto alguns reagiram de forma muito violenta, outros de modo surpreendente, não alterando em nada as relações existentes previamente entre eles. Entretanto, em um dos casos onde a reação envolveu violência física no momento do coming out, a mãe, que foi a protagonista das agressões, após alguns meses começou a estudar outras abordagens sobre a homossexualidade, de forma que o filho vê essa atitude como uma abertura à aceitação de sua sexualidade.

Apesar de observar variáveis como denominação religiosa, escolaridade e gênero, até o momento pouco foi possível apontar como esses fatores de fato interferem no desempenho dentro da família. De todas as variáveis consideradas, a única que apresentou alguma validade foi o tempo de conhecimento. Dos nove entrevistados, cinco consideram que, com o passar do tempo, o relacionamento tem melhorado, o que não significa que todas as famílias têm se aberto a essa questão, mas que os conflitos familiares foram em muito mitigados. Outros três consideram que o relacionamento continua o mesmo, e outro que o tempo não tem melhorado o relacionamento familiar.

Salientamos, aqui, que embora o preconceito e a discriminação aos homossexuais não tenha como causa única a religião, as justificativas dadas para a não aceitação são majoritariamente religiosas. Não é possível negar o forte teor discriminatório presente nos discursos evangélicos 
a respeito da homossexualidade. E se eles não são exclusivamente os responsáveis pela homofobia na sociedade brasileira, tampouco podemos negar que esses discursos não a fomentem em certa medida. Frases como "isso é uma abominação", "você vai pro inferno", “viado, sapatão e viciado pra mim devem estar mortos", "isso é pecado", "é ir contra a vontade de Deus", "gay não presta" foram ouvidos pela maioria dos entrevistados dentro do ambiente familiar. A crença na cura da homossexualidade esteve presente nos discursos de seis entrevistados, mostrando o quanto esses discursos ainda são apreendidos.

O sentimento de alguns de que a reação familiar tem como objetivo o desejo pelo seu "bem" não é unânime. Embora alguns compreendam que o desempenho de seus pais e mães simbolize o desejo de que seus filhos e filhas não vão para o inferno.

Acerca da questão da não aceitação da diferença, Sarti afirma:

A negação do diferente, a base etnocêntrica de todo o preconceito, funda-se precisamente na dificuldade de aceitar que o suposto diferente se parece muito conosco e pode nomear o que para nós é inominável. Na verdade, ele revela muito de nós mesmos e põe em questão o caráter absoluto de nossas próprias referências culturais. Se o outro pode estar certo, então, isso significa que nós podemos estar errados? (Cynthia SARTI, 2004, p. 22-23).

A reflexão de Sarti acerca desse processo de negação leva à consideração de questões mais primitivas, como talvez a uma atitude de autopreservação inconsciente, onde para manter sua segurança ontológica no mundo moderno ${ }^{16} \mathrm{o}$ indivíduo faça um esforço pela manutenção de certas doutrinas sobre as quais está estruturado.

No contexto familiar, a religião funciona como barreira ideológica no trajeto à aceitação. Talvez se coloque no caminho a dicotomia paz com Deus x paz com meu filho/filha. De forma que não se pode ter os dois, no momento em que um contraria um preceito do outro. Durkheim afirma que "a moral começa, pois, onde começa a ligação com um grupo, qualquer que ele seja” (Emilé DURKHEIM, 1970, p. 45). Dessa forma,

16 Giddens realiza uma reflexão acerca da segurança ontológica em: As consequências da Modernidade, e em A transformação da intimidade relaciona essa questão ao vício. 
podemos entender certas reações familiares como reflexo de um elo forte com o grupo religioso, de maneira que, em alguns casos esse elo se sobrepõe ao elo familiar. Outra leitura possível é o perverter dessa lógica, em benefício de um grupo com o qual se está mais ajustado e incorporado.

$\mathrm{Na}$ esfera familiar, a expectativa de reconhecimento afetivo é absoluta. O desejo dos indivíduos é serem amados por completo. O repúdio a uma característica individual tão marcante quanto a sexualidade é compreendido como não aceitação do indivíduo inteiro, revelando a condicionalidade do amor parental. O amor incondicional, percebido como próprio das relações entre mães e pais e seus filhos e filhas, em situações de conflito, ganha a oportunidade de provar sua existência por meio de atitudes. A expectativa do amor incondicional, mesmo que frustrada, faz parte da realidade social.

Giddens compreende o relacionamento puro como detentor de uma moral própria, essencialmente democrática. Em última instância, o que o autor revela é uma incompatibilidade entre a democracia das emoções e a discriminação de filhos e filhas, tendo por base sua sexualidade. Dessa forma, considerando as experiências vividas por homossexuais na sociedade, a família poderia servir como suporte a esses indivíduos, ao mesmo tempo como ferramenta de empoderamento, contrastando com a constante inferiorização construída pelos estigmas e estereótipos imputados à identidade homossexual no meio religioso evangélico. Quem acredita ser amado espera ser totalmente aceito, compreendido, acolhido, amparado e com isso, amado em sua individualidade. Na vida de pessoas LGBT, a urgência em estar protegido no ambiente familiar é ainda maior, uma vez que a experiência no espaço público é notadamente hostil com essas pessoas.

A moralidade específica às relações íntimas e familiares na modernidade, expressa na ideia de relacionamento puro, na qual os relacionamentos são ancorados na expectativa de trocas afetivas incondicionais, apesar de ser um constructo sociológico, é fundamental que gere expectativas morais nos indivíduos que possa sobrepujar outras concepções de moralidade. 


\section{REFERÊNCIAS}

DURKHEIM, Emilé. Sociologia e filosofia. Rio de Janeiro e São Paulo: Forense, 1970.

ENDJS $\varnothing$, Dag Øistein. Sexo e religião: do baile de virgens ao sexo sagrado homossexual. São Paulo: Geração Editorial, 2014.

ERIBON, Didier. Reflexões sobre a questão gay. Rio de Janeiro: Companhia de Freud, 2008.

FRESTON, Paul. Protestantes e política no Brasil: da Constituinte ao Impeachment, 303s. Tese de Doutorado em Sociologia. Departamento de Ciências Sociais no Instituto de Filosofia e Ciências Humanas da Universidade de Campinas, 1993.

GIDDENS, Anthony. As consequências da modernidade. São Paulo: Editora Unesp, 1991.

. A transformação da intimidade: sexualidade, amor e erotismo nas sociedades modernas. São Paulo: Editora da Universidade Estadual Paulista, 1993.

. O mundo em descontrole: o que a globalização está fazendo de nós. Rio de Janeiro: Record, 2007.

HONNETH. Axel. Luta por reconhecimento: a gramática moral dos conflitos sociais, 2. ed. São Paulo: Editora 34, 2009.

MACHADO, Maria das Dores Campos; PICCOLLO, Fernanda Delvalhas (Orgs.). Religiões e homossexualidades. Rio de Janeiro: Editora FGV, 2010.

NATIVIDADE, Marcelo. Homossexualidade, gênero e cura em perspectivas pastorais evangélicas. Revista Brasileira de Ciências Sociais, v. 21, n. 61, p. 115-132, jun./2006. Disponível em: <http://www.scielo.br/scielo.php?script=sci_arttext\&pid =S0102-69092006000200006>. Acesso em: 11 jan. 2016 .

NATIVIDADE, Marcelo; Oliveira, Leandro. As novas guerras sexuais: diferença, poder religioso e identidades LGBT no Brasil. Rio de Janeiro: Garamond, 2013.

RAMOS, Jair. A sexualidade como campo de batalha na internet: grupos religiosos e movimentos feministas e LGBT na luta em torno dos direitos sexuais. Reunião Brasileira

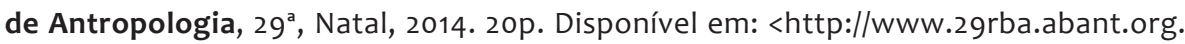
br/resources/anais/1/1401819505_ARQUIVO_SexualidadecomocampodebatalhaPaper-Dropbox.pdf>. Acesso em: 3 out. 2016.

SARTI, Cynthia. A Família como ordem simbólica. Psicologia USP, v. 15, n. 3, p. 11-28, 2004. Disponível em: <http://www.revistas.usp.br/psicousp/article/view/42289/45962>. Acesso em: 15 nov. 2016.

SEVERO, Julio. As ilusões do movimento gay. Independente, 2003.

. O movimento homossexual. Belo Horizonte: Editora Betânia, 1998.

Sheldon, Louis P. A estratégia: o plano dos homossexuais para transformar a sociedade. Rio de Janeiro: Central Gospel, 2012. 
TREVISAN, Janine Bendorovicz. Evangélicos pentecostais na política partidária brasileira: de 1989 a 2010. ANAIS DO IV ENCONTRO NACIONAL DO GT HISTÓRIA DAS RELIGIÕES E DAS RELIGIOSIDADES - ANPUH - Memória e Narrativas nas Religiões e nas Religiosidades. Revista Brasileira de História das Religiões. Maringá (PR) v. V, n. 15, jan./2013. Disponível em: <http://www.dhi.uem.br/gtreligiao/pub.html>. Acesso em: 10 dez. 2016.

. A atuação política pentecostal em confronto com o movimento LGBT no Brasil redemocratizado, 250s. Tese (Doutorado em Ciências Sociais) - Programa de Pós-Graduação em Ciências Sociais, PUCRS, Porto Alegre, 2015.

Submetido em: 19-9-2017

Aceito em: 1-12-2017

Mandrágora, v.23. n. 2, 2017, p. 49-69 